\title{
Influence of Leadership Behavior and Compensation Management on Job Satisfaction: Evidence from Taiwan
}

\author{
JIA-YANG LIN \\ Graduate Institute of Business and Management, National Formosa University \\ Yunlin County, Taiwan. \\ E-mail: yang8833332277@gmail.com \\ TSENG-CHUNG TANG \\ Department of Business Administration, National Formosa University. \\ LI-CHIU CHI \\ Department of Applied Foreign Languages, National Formosa University.
}

\begin{abstract}
This study aims to explore the influence of leadership behavior and compensation management on job satisfaction. This study suggested that there was a significant positive correlation between leadership behavior and compensation management. In addition to leadership behavior, providing rewards for employees appropriately will improve their productivity and competitiveness. There was a significant positive correlation between compensation management and job satisfaction. Providing and fulfilling the standards for compensation management will improve job satisfaction and efficiency of employees. There was a significant positive correlation between leadership behavior and job satisfaction as well. When leaders have a good relationship with employees, employees will get more support and attention, leading to the increase in their job satisfaction. Last, according to the research results, leadership behavior and compensation management can be used to predict job satisfaction since it is heavily influenced by the two. In other words, leadership behavior and a sound compensation management system can significantly and positively measure job satisfaction and further predict the employment and retention of employees.
\end{abstract}

Keywords: Leadership Behavior, Compensation Management, Job Satisfaction.

\section{Introduction}

With the rapid development of information nowadays, employees exchange information highly depending on the Internet and gradually become alienated from their colleagues, partners or team members in reality; ultimately, they cannot reach a consensus and loss the passion and aim for work. According to the "Survey of Interpersonal Relationships at Workplace" conducted by Wu (2017), 70\% of the young employees in Taiwan changed their jobs because they were unable to get along with colleagues. The result of the survey conducted by CommonWealth Magazine in 2015 shows that respects from peers influenced job satisfaction the most. Thus, employees are likely to resign if they are not respected regardless of good salaries (Chang, 2015). Therefore, how to maintain harmonious communication between peers is a big challenge for management and leaders.

The factors in the retention system include human resources and organization. Locke (1982) compared four incentives, namely goal setting, employee involvement, job enrichment and money and found that money 
was the most effective. For most employees, the most key factor in retention is to measure the appropriateness of service by salary. For businesses, human resources are costly; how to employ and retain outstanding employees are an important and incoming challenge and the key to success for businesses. Compared with employees with lower thresholds, working conditions and needs of employees with higher thresholds and factors in job satisfaction are often considered beyond existing salary and benefits and. CommonWealth Magazine also summarized the ten reasons for top talents' resignation on Forbes in 2012, namely failure to unleash their passions, failure to challenge their intellect, failure to engage their creativity, failure to develop their skills, failure to give them a voice, failure to care, failure to lead, failure to recognize their contributions, failure to increase their responsibility, and failure to keep commitments (Myatt, 2012). Ma (2013) pointed out that the reason for talent leave was not enough salary and feeling wronged. The reason for low job satisfaction and even resignation is nothing more than money and feeling. The goal of this study is to explore the correlation between leadership behavior and compensation management (independent variables) and job satisfaction (dependent variable). Through analysis and exploration, this study hopes to have a thorough understanding of conditions that affect job satisfaction and propose recommendations for improving the turnover rate and job satisfaction in businesses.

\section{Literature Review}

\section{Leadership Behavior}

Tead (1935) indicated that leadership is an act to influence others for the purpose of achieving a goal together. A leader is a person who is able to influence the entire group. Meng and Tian (2015) thought that the prerequisite of being a leader must is to keep advanced and innovative, so as to promote coordination within the organization and employees' passion for work, further improving performance and productivity. Reynolds (1999) thought that leadership is an act of an individual to influence a group and lead the group in a unique way after understanding. Charm and power are important factors in the process of leadership. In addition, Burns (1978) divided leadership style into transformational leadership and transactional leadership. Transformational leaders achieve spiritual ascension by improving the highest level of demand, while transactional leaders reach an agreement with employees to complete tasks by providing tangible or intangible things. The main difference between transformational leadership and transactional leadership is that transformational leadership is built on the demand, namely spiritual level of employees to achieve self-actualization, while transactional leadership coordinates employees' efforts to complete work or organizational goals together (Mitchell \& Tucker, 1992). Many scholars believe that transformational leadership is closely related to transactional leadership and both types of leadership can coexist in line with suitable policies. Both transformational leadership and transactional leadership are ways to enhance job satisfaction. Leaders shall maneuver transformational leadership and transactional leadership impartially in the process of leadership to make organizations go beyond the organizations (Wright, 1988; Kotter, 1990; Sergiovanni, 1990; Mitchell \& Tucker, 1992; Tang \& Chi, 2001). To improve employees' identification, leaders shall lead by example and morals, care for employees in terms of life, work, and growth, and reward employees' contributions in a fair and proper manner, so as to maximize employees' identification of leadership behavior (Lee \& Lin, 2013). In terms of the Two Factor Theory, transactional leadership plays a role of hygiene, while transformational leadership plays a role of motivator. Both factors are interdependent (Chen \& Shi, 2014).

\section{Compensation Management}

Huang (1989) believed that compensation is an important part of human resources management; it is an income from the provision of labor and service and the price for rights of employers by exercise of obligations under labor contracts; it is also the basis for maintaining the need of living and changing the level of life. A sound compensation management system brings labor stability and a direction of future development, which can significantly increase loyalty and contributions to an organization; the importance and function of remuneration in an organization define compensation management. In the process of human 
resources management, a certain principle of compensation management must be followed to encourage employees in an effective way (Chang, 2010).

Lawler (1984) stated that well-designed compensation system and management are crucial to an improved business performance.For employees, compensation is feedback on employees' performance and recognition of employees' capabilities or achievements; for an organization, compensation is a cost and an expense as well as a competitive advantage; for society, compensation affects the distribution of wealth and thus is the symbol of fairness and justice. Accordingly, compensation is diverse and of far-reaching influences (Chang, 1996). Lee and Mao (1980) asserted that an organization mainly pays salaries to its employees for service rendered, so it sets up a reasonable compensation system and implements, adjusts, and controls the system systemically (Wu, 2005). For businesses, appropriate salaries are offered to remain competitive and retain and attract talents. To meet diverse goals, multiple basic elements must be considered in the process of designing a compensation system, including performance, skills, positions, and healthcare (Jiang, Xiao, Qi, \& Xiao, 2009; Chu, Chi, \& Lee, 1996). Gupta (2014) mentioned that businesses having reasonable compensation management not only can make employees work happily, but also can improve employees' attitude toward work, quality and productivity. The main function of compensation is to encourage employees' efficiency and further maximize the application of human resources; compensation management should include a set of guidelines, strategies, skills, and steps (Osibanjo \& Adeniji, 2013). Lee (2005) illustrated that in addition to a comfortable working environment, interpersonal relationships within an organization, and more participation in decision-making, it is more difficult to compensate employees for challenges, a sense of achievement and a higher level of development by way of money; moreover, compensation management benefits corporate cultures considerably and maintains a stable labor/management relation (Chang, 2010).

\subsection{Job Satisfaction}

Hoppock (1935) pointed out that job satisfaction refers to workers' physical and mental satisfaction with factors related to a working environment and workers' subjective perception of work itself. Porter and Lawler (1968) proposed that the degree of job satisfaction is defined by the gap between the actual compensation and the expected compensation for a job. The smaller the gap in the personal compensation, the higher the job satisfaction; the bigger the gap in the personal compensation, the lower the job satisfaction. Locke (1976) indicated that the goal of life is not only happiness but also career development, such as turnover rate, absenteeism, costs of employment, productivity, costs of industrial conversion, and labor relations. Spector (1985) pointed out that main factors in job satisfaction included salaries, promotion, interpersonal relationships, benefits,rewards, job attributes, and communication.

According to Liang and Lo (2015), employees' psychological capital has a direct impact on job satisfaction; thus, when employees have a good mental state, they can enhance their own job satisfaction and further render good service; however, labor productivity and quality of professional life within an organization are two core issues of human resources management. Job satisfaction is an important mental indicator of quality of professional life. According to Liang and Wang (2014), to improve job satisfaction, efficiency must be improved at the same time, so that better service can be offered to consumers. Job satisfaction is generally divided into three types. The first is overall satisfactions.

Kalleberg (1977) corroborated out that the overall satisfaction is an attitude derived from the feeling of work itself and the working environment and the overall reaction to work; overall satisfaction is balanced by the satisfying and unsatisfying aspects of work; the second is expectation discrepancy. Porter and Lawler (1968) argued that job satisfaction is the gap between the actual compensation and the expected compensation for a job. The smaller the gap, the higher the job satisfaction; instead, the bigger the gap, the lower the job satisfaction; the third is frame of reference. Smith, Kendall, and Huilin (1969) indicated that job satisfaction is an explanation of working characteristics based on the frame of reference and measured by work, pay, promotions, supervision, and coworkers. 


\section{Methodology}

This study aims to explore the relationship among leadership behavior, compensation management and job satisfaction. According to the literature review, the methodology is proposed in this section, covering research hypotheses, subject and measurement, and analyses.

\section{Research Framework}

This study defined leadership behavior and compensation management as independent variables and defined job satisfaction as a dependent variable to explore the influence of independent variables on the dependent variable. The research framework is as shown Figure 1.

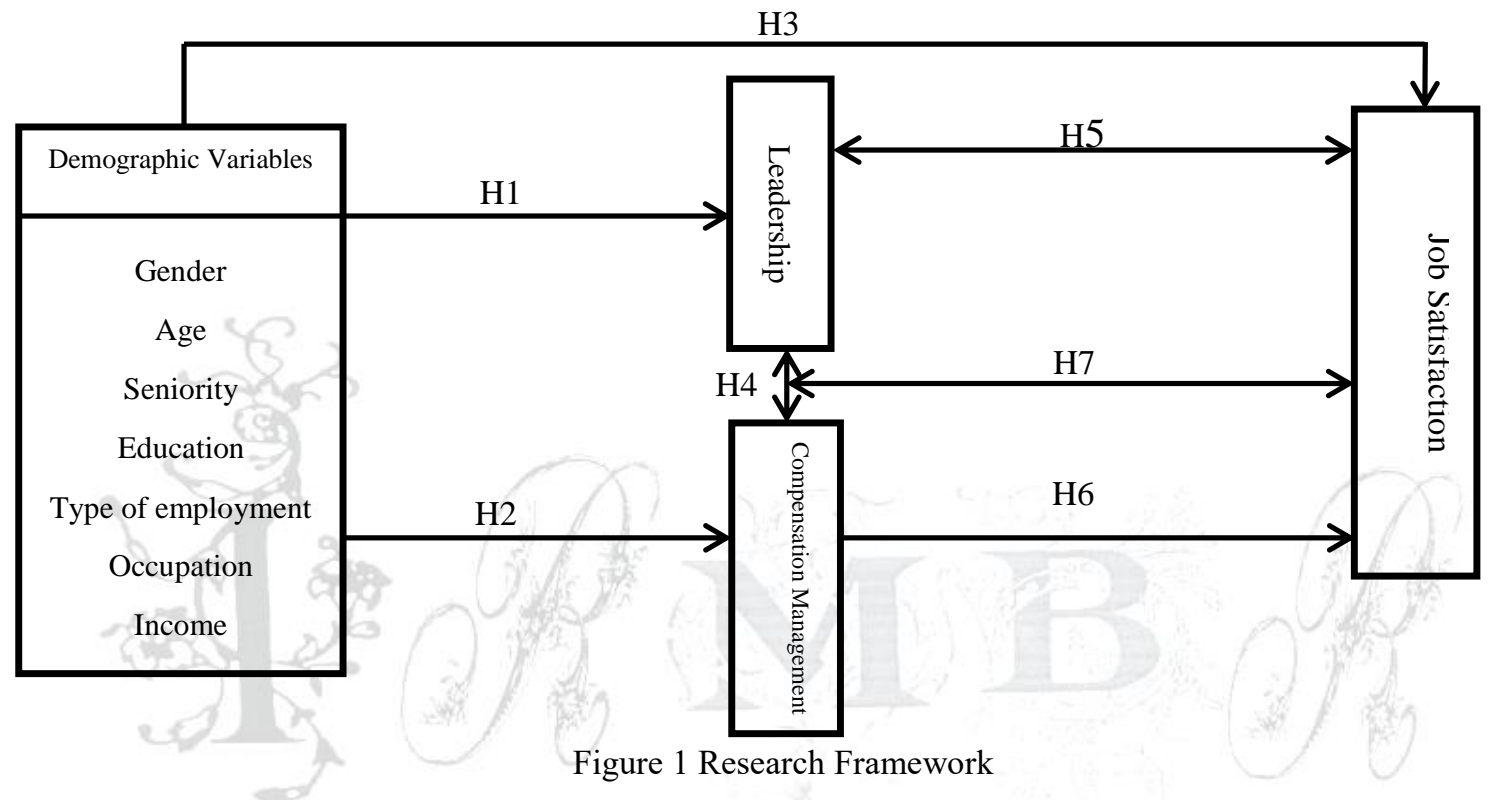

\section{Research Hypothesis}

This study proposed the following hypotheses with regard to demographic variables, leadership behavior, compensation management, and job satisfaction based on the research purpose and framework.

H1: There exists a significant difference among the different aspects of leadership behavior across the various demographic variables.

$\mathrm{H} 2$ : There exists a significant difference among the different aspects of compensation management across the various demographic variables

H3: There exists a significant difference among the different aspects of job satisfaction across the various demographic variables

H4: There is a significant correlation between leadership behavior and compensation management.

H5: There is a significant correlation between leadership behavior and job satisfaction.

H6: There is a significant correlation between compensation management and job satisfaction.

H7: There are significant effects of leadership behavior and compensation management on job satisfaction.

\section{Research Subject and Measurement}

This study conducted an on-line survey of the influence of leadership behavior and compensation management on job satisfaction and retrieved 404 valid questionnaires in total. 
The survey is divided into four parts and consists of 46 questions. The first part is demographic variables; the second part is leadership style, the third part is compensation management; the fourth part is job satisfaction. The detailed measurement is described below:

\section{Demographic Variables}

The purpose of the demographic variables is to understand the background of respondents, including gender, age, seniority, education, type of employment, occupation, and income.

\section{Leadership Behavior}

\section{(1) Transformational Leadership Behavior}

The seven major dimensions presented by Podsakoff, MacKenzie, Moorman, and Fetter (1990) were adopted for design of this questionnaire; namely inspiring intelligence, positive encouragement, respecting feelings, cooperation, high expectation, setting examples, and depicting the future.

\section{(2) Transactional Leadership Behavior}

Compiled based on the questionnaire proposed by Podsakoff et al. (1990), the transactional leadership behavior questionnaire is divided into five factors, namely subsequent rewards, non-subsequent rewards, subsequent punishments, non-subsequent punishments, and feedback on punishments.

\section{(3). Compensation Management}

\section{(1) Healthcare Efficacy}

This study compared conditions provided by the company with those provided by the same trade based on the standards for external equity. Healthcare refers to whether basic salaries, allowances, medical insurance and basic needs in life provided by the company meet the needs of employees; the content and nature of a position, workplace, and surroundings are also considered.

\section{(2) Position Efficacy}

Internal equity is measured by whether service rendered by individuals meets the compensation obtained at the same level; personal performance and skills are measured by special performance rendered in service, special skills and certificates obtained, and rewards corresponding to personal contributions in service.

\section{(3). Job Satisfaction}

According to the Minnesota Satisfaction Questionnaire designed by Smith, Kendall, and Hulin (1969) and Weiss, Dawis, England, and Lofquist (1967), the research divided job satisfaction into compensation satisfaction, promotion satisfaction, coworker satisfaction, job satisfaction, and overall satisfaction.

\section{Data Analysis}

After the questionnaires collecting and eliminating the uncompleted questionnaires, the study codes and inputs the data. Descriptive statistics such as frequency, mean, and standard deviation were employed to investigate the data. Inferential statistics such as $t$-tests, one-way analysis of variance (ANOVA), correlation and multiple regression analysis were utilized to explore relationships among variables. 


\section{Research Result}

\section{Descriptive Statistics}

This study adopted the online survey to avoid the geographic restrictions. A total of 404 valid questionnaires were retrieved for further data analysis. In the demographic variables, $59.9 \%$ of the respondents were females; most of the respondents were workers aged 24 or below, accounting for $37.6 \%$; most of the respondents worked for 16 years or more, accounting for $25.7 \%$; most of the respondents were bachelor's degree holders, accounting for 58.2\%; most of the respondents were full-time workers, accounting for $83.4 \%$, most of them worked in the service industry (33.4\%); and $32.9 \%$ had income under NT $\$ 28,000$ or below.

Regarding the perception of leadership behavior, the five questions with the highest average were "Supervisors will request us to abide by the discipline of work" $(\mathrm{M}=3.92, \mathrm{SD}=0.92)$, "Supervisors will not interfere if work is done in line with the working routine" $(\mathrm{M}=3.8, \mathrm{SD}=1.04)$, "Supervisors will pay attention to our misconduct and errors at any time" $(\mathrm{M}=3.77, \mathrm{SD}=0.86)$, "Supervisors will tell us that we must work hard to get rewarded" $(\mathrm{M}=3.72, \mathrm{SD}=0.92)$, and "Supervisors will provide assistance in a timely manner when we encounter difficulties in work" $(\mathrm{M}=3.63, \mathrm{SD}=1.08)$.

Regarding the perception ofcompensation management, the five questions with the highest average were "Basic salaries, additional pays, allowances, bonuses, dividends, and benefits are clearly defined" (M=3.60, $\mathrm{SD}=1.07$ ), "The compensation structure (or position rank) is clearly defined" ( $\mathrm{M}=3.58, \mathrm{SD}=1.07$ ), "Personal performance is considerably emphasized in the approval of compensation or planning of raise" $(\mathrm{M}=3.53, \mathrm{SD}=1.02)$, "I am well aware of how to work hard to get a higher pay" ( $\mathrm{M}=3.53, \mathrm{SD}=1.1)$, and "Compensation is given differently depending on personal skills and capabilities" (M=3.48, $\mathrm{SD}=1.06)$.

Regarding job satisfaction, the five questions with the highest average were "Getting along with colleagues" ( $\mathrm{M}=3.94, \mathrm{SD}=0.91)$, "Work stability" $(\mathrm{M}=3.85, \mathrm{SD}=0.86)$, "Work autonomy" $(\mathrm{M}=3.76$, $\mathrm{SD}=0.97)$, "Sense of achievement" $(\mathrm{M}=3.64, \mathrm{SD}=0.93)$, and "Work content and environment" $(\mathrm{M}=3.6$, $\mathrm{SD}=.096)$.

\section{Reliability \& Validity Analysis}

The Cronbach alpha coffificients of transformational leadership, transactional leadership, healthcare efficacy, position efficacy, leadership behavior, compensation management, and job satisfaction are 0.954, $0.858,0.901,0.921,0.949,0.952$, and 0.939 , respectively. According to the empirical results, all Cronbach's alpha coefficients are greater than 0.80 . This suggests that all of the research items are reliable and the entire test is internally consistent (Kline, 2000; DeVellis, 2012).

The item analysis was conducted to examine whether each question has the capacity of identifying the reactions of different respondents. This study adopted Levene to test the homomorphism or heterogeneity of two groups of population variations and further conducted the $t$-test to examine the variance in each question. The $p$ value in 39 questions showed statisticcally significant, while "Supervisors will request us to perform better than other units" ( $\mathrm{F}=4.813, p=0.068)$ and "Supervisors only request us to perform tasks required for work" $(\mathrm{F}=1.578, p=0.053)$ showed no significance. This study deleted these two questions and kept the remaining questions that could identify the different reactions of two groups and respondents.

Construct validity refers to measurement of theory or extent of the trait, namely measurement of cohesion between aspects. This study conducted the exploratory factor analysis of leadership behavior, compensation management and job satisfaction. For the pre-test of factor analysis, if variables have common variability, the factor analysis can be conducted only when Bartlett's $p$ value is close to zero and KMO (measure of sampling adequacy) is over 0.6 (Kaiser, 1974). The result of the research is shown in Table 1. 
Table $1 \mathrm{KMO}$ and Bartlett's Test

\begin{tabular}{|l|c|c|}
\hline Dimension & $\begin{array}{c}\text { KMO Measure of } \\
\text { Sampling Adequacy }\end{array}$ & $\begin{array}{c}\text { Bartlett's Sphericity Test Approx. } \\
\text { Chi-square }(p)\end{array}$ \\
\hline Leadership Behavior & 0.946 & $5086.511(.000)$ \\
\hline Compensation Management & 0.919 & $3151.440(.000)$ \\
\hline Job Satisfaction & 0.891 & $1589.790(.000)$ \\
\hline
\end{tabular}

This study deleted valid samples with worse explanations and kept research questions with the factor eigenvalue over 0.6 and the factor loading over 0.5 .

Regarding the leadership behavior, three factors were extracted from the factor analysis and named "Supervisors will consider colleagues' feelings", "Rewards are provided", and "Rules must be followed" respectively; among these three factors, ten questions were about "Supervisors will consider colleagues' feelings" with eigenvalue 8.59 , which explains $55.939 \%$ of the total dispersion. The higher this factor is scored, the higher the identification of the company's management system. Three questions were about "Rewards are provided" with eigenvalue 1.382, which explains $8.637 \%$ of the total dispersion. The higher this factor is scored, the higher satisfaction the overall reward system. Three questions were about "Rules must be followed" with eigenvalue 1.022 , which explains $6.386 \%$ of the total dispersion. The higher this factor is scored, the higher obedience at work. The respective Cronbach alpha of these three factors is 0.956, 0.642 , and 0.5 , which are satisfactory.

Regarding the compensation management, two factors were extracted from the factor analysis and named "Professional skills are evaluated in the compensation system" and "Standard measurement is adopted in the compensation system"; among these two factors, nine questions were about "Professional skills are evaluated in the compensation system" with eigenvalue 6.905 , which explains $53.113 \%$ of the total dispersion. The higher this factor is scored, the higher the identification of the company's compensation management. Four questions were about "Standard measurement is adopted in the compensation system" with eigenvalue 1.307 , which explains $10.530 \%$ of the total dispersion.. The cumulative total variance of these two factors was $63.166 \%$. The higher this factor is scored, the fairer the company's compensation management in terms of contributions to the position. The respective Cronbach alpha of these two factors is 0.804 and 0.913 , which are particularly satisfactory.

Regarding the job satisfaction, only one factor was extracted from the factor analysis and named "Work process satisfaction" with eigenvalue 4.525 , which explains $56.564 \%$ of the total dispersion. The higher this factor is scored, the higher the perception of personal performance and resources provided by the company. The reliability is $a=0.891$, which is satisfactory.

\section{Analysis of Variance}

This section aims to investigate the difference among leadership behavior, compensation management and job satisfaction across the various demographic variables by employing $t$-test and ANOVA.

\section{Difference of Demographic Variables on Leadership Behavior}

The independent sample $t$-test revealed a statistically significant difference across gender on "Rules must be followed" $(t=2.482, p=0.013)$. The one way ANOVA revealed a statistically significant difference on "Supervisors will consider colleagues' feelings" among age groups ( $\mathrm{F}=4.647, p=0.000)$, seniority groups ( $\mathrm{F}=5.629, p=.000)$, education groups $(\mathrm{F}=3.813, p=.000)$, and occupation groups $(\mathrm{F}=9.28, p=.000)$. The ANOVA also revealed a statistically significant difference on "Rules must be followed" among age groups $(\mathrm{F}=6.313, p=.000)$, seniority groups $(\mathrm{F}=5.683, p=.000)$, education groups $(\mathrm{F}=7,422, p=.000)$, occupation groups $(\mathrm{F}=6.548, p=.000)$, and income groups $(\mathrm{F}=4.289$, $p=0.001)$. 


\section{Difference of Demographic Variables on Compensation Management}

The one way ANOVA revealed a statistically significant difference on "Standard measurement is adopted in the compensation system" among seniority groups ( $\mathrm{F}=3.219, p=0.007)$, education groups $(\mathrm{F}=3.669$, $p=0.012)$, occupation groups $(\mathrm{F}=2.936, p=0.013)$, and income groups $(\mathrm{F}=3.499, p=0.004)$. The ANOVA also revealed a statistically significant difference on "Professional skills are evaluated in the compensation system" among occupation groups $(\mathrm{F}=3.025, p=0.011)$, and income groups $(\mathrm{F}=2.921, p=0.013)$.

\section{Difference of Demographic Variables on Job Satisfaction}

The one way ANOVA revealed a statistically significant difference on "Work process satisfaction" among seniority groups $(\mathrm{F}=2.505, p=.03)$, education groups $(\mathrm{F}=2.953, p=0.032)$, and income groups $(\mathrm{F}=5.12$, $p=0.007$ ).

\section{Correlation Analysis}

To investigate the relationship between independent variables (leadership behavior and compensation management) and dependent variable (job satisfaction), Pearson correlation analysis was adopted to find out the direction and strength of relationship between the research variables of this study.

\section{Correlation Between Leadership Behavior and Compensation Management}

The empirical results suggested that there is a statistically significant correlation between different leadership behavior and compensation management. All of the compensation management factors, "Professional skills are evaluated in the compensation system" and "Standard measurement is adopted in the compensation system", were connected to three factors of leadership behavior. These factors were "Supervisors will consider colleagues' feelings", "Rewards are provided", and "Rules must be followed". The revealed correlations were mainly of medium intensity ( $r=.439 \sim .601)$, in few cases, low ( $r=.245 \sim .293)$. From the research findings of this study, it could be concluded that the impact of leadership behavior on compensation management existed. These research findings are consistent with the results of Chang (2002) and $\mathrm{Wu}$ (2005) and additionally supported the assertion about the impact of leadership behavior on compensation management. This also could suggest that a set of complete leadership models should work with a set of complete compensation management systems. Only through professional training and standards for compensation measurement can businesses improve employees' competitiveness consistently.

\section{Correlation of Leadership Behavior and Job Satisfaction}

Statistically significant positive correlations between all three factors of leadership behavior, "Supervisors will consider colleagues' feelings", "Rewards are provided", and "Rules must be followed" and job satisfaction were found in this study. All revealed correlations were of low to medium intensity $(r=.247 \sim .620)$, the existence of the positive link between leadership behavior and job satisfaction was confirmed. This indicates that effective and positive leadership behavior, timely care, appropriate reward systems, and existing standards can improve job satisfaction effectively.

\section{Correlation of Compensation Management and Job Satisfaction}

Statistically significant positive and strong correlations between compensation management factors, "Professional skills are evaluated in the compensation system" and "Standard measurement is adopted in the compensation system", and job satisfaction were revealed in this study. All defined correlations were of medium intensity $(r=.540 \sim .620)$, therefore, it could be concluded that there was a positive relationship between compensation management and job satisfaction. This indicates that a set of complete 
compensation management systems that evaluate employees' competence and skills based on the fair, just, and open standards for compensation measurement can improve job satisfaction effectively.

\section{Regression Analysis}

There may be a link among leadership behavior, compensation management, and job satisfaction. Thus, this study adopted the multiple regression analysis to find out the relationship among leadership behavior, compensation management, and job satisfaction.

In the leadership behavior, "Supervisors will consider colleagues' feelings" $(\beta=.207, p<.001)$ and "Rewards are provided" $(\beta=.194, p<.001)$ had a positive impact on job satisfaction, while "Rules must be followed" ( $\beta=-.102, p<.001)$ had a negative impact on job satisfaction. This indicates that an organization with appropriate leadership behavior not only can make employees work happily, but also can motivate their morale.

In the compensation management, "Professional skills are evaluated in the compensation system" $(\beta=.218$, $p<.001)$ and "Standard measurement is adopted in the compensation system" $(\beta=.282, p<.001)$ had a positive impact on job satisfaction. This also indicates that a sound compensation management system can effectively improve the future development of the entire business. Sound compensation management has a positive impact on human resources management.

\section{Conclusions and Recommendations}

\section{Conclusions}

According to the research, employees of different seniority, educations, and income showed a significant difference in leadership behavior, compensation management and job satisfaction. There was a significantly positive correlation between leadership behavior and compensation management, which is consistent with the previous literature. Therefore, leadership behavior and appropriate reward systems will improve employees' productivity and competitiveness. There was a significantly positive correlation between compensation management and job satisfaction. If businesses can provide and fulfill the standards for compensation management, employees'job satisfaction and efficiency will be improved. There was a significantly positive correlation between leadership behavior and job satisfaction. When leaders maintain a good relationship with employees, employees will get more support and attention, leading to the increase in their job satisfaction. Last, leadership behavior and compensation management positively influenced and significantly forecasted job satisfaction; in other words, leadership behavior and a sound compensation management system can significantly and positively measure job satisfaction and further forecast employment and retention of employees.

\section{Recommendations}

\section{Recommendations to Businesses}

1. Improving leadership behavior can increase job satisfaction through internal and external methods. For internal methods, also known as the virtual level, executives or management provide employees spiritual supply, such as encouragement and excitement, to make them feel satisfied when rendering service; that is, transformational leadership is offered to improve employees' sense of belonging and achievement and make employees feel respected and irreplaceable; opportunities for training can be providedwhenever necessary to allow employees to advance and become more productive. Kazmi and Naaranoja (2013) pointed out that an organization under the transformational leadership can achieve more creativity and productivity; the degree of job satisfactiondepends on th working environment, flexibility, creativity, independence, and goal setting (Mihalcea, 2013); for external methods, also known as the 
substantive level, moderate exchange of conditions is offered to employees in a timely manner to make employees feel satisfied with rewards in addition to salary; the aforesaid rewards can be employee travel, gatherings, or leave, which are offered to encourage employees to make more contributions and efforts to the businesses.

2. For businesses, the cost of human resources accounts for the largest percentage of the total cost. Thus, businesses intend to control the cost through compensation management. How to make employees feel satisfied and control resources of the entire business at the same time is a key to compensation management; for employees, the literature of the research mentioned four factors, namely performance, skills, positions, and healthcare ((Jiang, Xiao, Qi, \& Xiao, 2009; Chu, Chi, \& Lee, 1996). To meet employees' satisfaction with compensation, the abovementioned factors must be properly evaluated; in addition, the convincing standards for measurement of service rendered by employees must be set up to balance employees' feelings and businesses' cost of compensation.

The compensation theory includes intrinsic rewards and extrinsic rewards (Robbins, 1978). Intrinsic rewards use some virtual models to improve employees' feelings, such as participation in decision-making, freedom and discretion of work, and opportunity for personal development, and provide employees rewards in addition to salaries; extrinsic rewards are internal reward systems offered to meet employees' mental satisfaction with service rendered, such as employee benefits, reward systems, raise, and promotion, and further improve employees' job satisfaction, willingness to serve businesses, and loyalty to businesses.

3. This study compiled the results of analyses andproposed ways to improve employees'job satisfaction in terms of leadership behavior and compensation management, which can help employees find personal achievements and value within businesses and organizations, increase their contributions and loyalty to businesses, and avoid the decrease in efficiency and an idea of transfer. Through these ways, the cost of human resources will be reduced and the human resources will be optimized. The ways to improve job satisfaction in terms of leadership behavior and compensation management are shown in Table 2 below.

Table 2 Ways to Improve Job Satisfaction

\begin{tabular}{|l|ll|}
\hline \multirow{3}{*}{$\begin{array}{l}\text { Beadership } \\
\text { Behavior }\end{array}$} & 1. & Businesses must design a set of complete employee training programs. \\
\cline { 2 - 3 } & 2. & Leaders must provide employees spiritual excitation in a timely manner. \\
\cline { 2 - 3 } & 3. & Businesses must provide additional reward systems appropriately. \\
\cline { 2 - 3 } $\begin{array}{l}\text { Compensation } \\
\text { Management }\end{array}$ & 1. & $\begin{array}{l}\text { Opportunities for academia training are provided for employees to improve their } \\
\text { management skills. }\end{array}$ \\
\cline { 2 - 3 } & $\begin{array}{l}\text { Businesses must set up and implement a set of fair, just, and open compensation } \\
\text { systems. }\end{array}$ \\
\cline { 2 - 3 } & $\begin{array}{l}\text { Businesses should include special skills, technology or languages in the } \\
\text { calculation of salary. }\end{array}$ \\
\cline { 2 - 3 } & $\begin{array}{l}\text { Regular gatherings and travel should be planned to bridge the gap between the } \\
\text { employees. }\end{array}$ \\
\cline { 2 - 3 } & 4. & Businesses should allow for some employees to conduct field studies. \\
\hline
\end{tabular}

\section{Recommendations for Future Research}

1. The subject of the research is too broad. Future researchers are recommended to narrow the types of industry or target specific industries to make research more helpful to the understanding of different industrial practices and characteristics.

2. This study focused more on the salaries, performance bonuses, and incentives of compensation management and did not cover benefits and service. Future researchers are recommended to cover benefits and service provided by businesses to enhance the contribution of research. 


\section{References}

Anderson, T. D. (1992), Transforming leadership: New skills for an extraordinary future. Amherst, MA, Human Resource Development Press.

Burns , J.M. (1978), Leadership, New York: Harper \& Row.

Chang, J. Q. (2010), On compensation management, human resource, Modern Business, 6B, 182.

Chang, Y. Q. (2015), More money is useless, employees want is respect, CommonWealth Magazine, from the World Wide Web: http://www.cw.com.tw/article/article.action?id=5067582.

Chen, W. J. \& Shi, K. (2014), The structure and measurement of transactional leadership in China, Chinese Journal of Management, 11(10), 1456-1459.

Chu, C. M. Chi, S. C. \& Lee, C. G. (1996), A review on literatures of pay design-building "The four paydesign factors model, Journal of Human Resource Management, 6, 57-89

DeVellis, R. F. (2012). Scale development: Theory and applications. Los Angeles: Sage. 109-110.

Gupta, M. (2014), Employees' satisfaction towards monetary compensation practices, Global Journal of Finance and Management, 6(8), 757-764.

Hoppock, R. (1935), Job satisfaction, New York: Harper Brothers.

Huang, Z. Y. (1989), Human resource management, Taipei: Hwa Tai Publishing.

Jiang, Z., Xiao, Q., Qi, H., \& Xiao, L. (2009), Total reward strategy: A human resources management strategy going with the trend of the times, International Journal of Business and Management, 4(11), 177-183.

Kaiser, H.F. (1974), An index of fovtorical simplicity, Psychometrika, 39, 31-36.

Kalleberg, A. L., (1977), Work values and job rewards: A theory of job satisfaction, American Sociological Association, 42(1), 124-143.

Kazmi, S.A.Z. \& Naaranoja, M. (2013), Connecting individual differences in workforce to organizational creativity through transformational leadership for corporate transformational effectiveness, Open Journal of Leadership, 2(4), 73-77.

Kline, P. (2000), The handbook of psychological testing (2nd ed.). London: Routledge, 3.

Kotter, J.P. (1990), A force for change: How leadership differs from management, New York: Free Press.

Lee, J. H. \& Mao, J. L. (1980), Compensation system and management practices, Taipei: Super A Plus Consultant Services Co., Ltd.

Lee, X. Q. \& Lin, Z. Y. (2013), An empirical comparison of transformational and transactional leadership effectiveness, Journal of Xiamen University of Technology, 21(1), 69-73.

Leithwood, K. A. (1992). The move toward transformational leadership, Educational Leadership, 49(5), 812.

Li, C. W. (2005), On comprehensive compensation management, Market Modernization, 446, 226-227.

Liang, S. J. \& Wang, P. C. (2014), Collection of residential communities in guard security personnel job satisfaction factors: Taipei area as an example, Journal of Criminology, 17, 63-88.

Liang, W. K. \& Lo, Z. H. (2015), A study of relationships among internal service quality, Psychological Capital and Job Satisfaction, Management information computing, 4, 249-262

Lin, H. M. (1995), A comparison of school leaders and business leaders in transition leader, Graduate Institute of Administration and Policy of National Chengchi University.

Liontos, L. B. (1992), Transformational leadership, ERIC Document Reproduction Service No.ED347 636.

Locke, E. A. (1976), The nature of causes of job satisfaction, In M. D. Dunnette (Ed.), Handbook of industrial and organizational Psychology, Chicago, IL: Rand McNally, 1297-1349.

Locke, E. A. (1982), Relation of goal performance with a short work period multiple goal levels, Journal of Applied Psychology, 67, 512-514.

Ma, Y. (2013), Why did the employee resign? , Ma Yun philosophical quotations, from the World Wide Web: http://tw.weibo.com/1895250515/3559019798684077.

Meng, Y. \& Tian, Y. Z. (2015), An empirical research on correlation between leadership behavior and performance in a manufacturing enterprise based on leadership values, Chinese Journal of Management, 21(1), 1313-1318. 
Mihalcea, A. (2013), The impact of leader's personality on employees' job satisfaction: Procedia , Social and Behavioral Sciences , 8, 90-94.

Mitchell, D. E., \& Tucker, S. (1992), Leadership as a way of thinking, Educational Leadership, 49(5), 3035.

Mohrman, A. M. \& L. L. Lawler, (1984), A review of theory and research, in F. W. McFarlan (ed.), The Information Systems Research Challenge, Boston, MA: Harvard Press, 135-164.

Myatt, M. (2012), 10 Reasons Your Top Talent Will Leave You. Forbes -Leadership, Retrieved from https://www.forbes.com/sites/mikemyatt/2012/12/13/10-reasons-your-top-talent-will-leaveyou/\#6cf4b0f538a6.

Nanus, B. (1992), Visionary leadership: creating a compelling sense of direction for your organization, San Francisco: Jossey-Bass.

Osibanjo, O. A. \& Adeniji, A. A. (2013), Impact of organizational culture on human resource practices: A study of selected Nigerian private universities, Journal of Competitiveness, 5(4), 115-135.

Podsakoff, P. M., MacKenzie, S. B., Moorman, R. H. \& Fetter, R. (1990), Transformational leader behaviors and their effects on followers' trust in leader, satisfaction and organizational citizenship behaviors, Leadership Quarterly, 1(2), 107-142.

Porter, L. W., \& Lawler, E. E., (1968), Managerial attitudes and performance, Homewood: R.D. Irwin.

Reynolds, K. (1999), I am their leader, I must follow them, Management Accounting, 7(7), 70-71.

Robbins, S. P. (1978), Personnel: The management of humanresources, Englewool Cliffs \& New Jersey: Pr entex-Hill.

Sergiovanni, T. J. (1990), Value-added leadership: How to get extraordinary performance in schools, New York: Harcourt Brace Jovanovich.

Smith, P. C., Kendall, L. M., \& Hulin, C. L. (1969), The measurement of satisfaction in work and retirement, Chicago: Rand McNally.

Spector, P. E., (1985), Measurement of human service staff satisfaction: development of the job satisfaction survey, American journal of community psychology, 13(6), 693-713.

Tang, T. C. \& Chi, L. C. (2001), On transformational leadership and transactional leadership, Journal of Chia Institute of Technology, 22, 1-22.

Tead, O. (1935), The art of leadership, American Journal of Sociology, 41(3), 376-377.

Vroom, V. H. (1964), Work and motivation, NY: John Wiley \& Sons.

Weiss, D. J., Dawis, R. V., England, G. W., Lofquist, L. H. (1967), Manual for the Minnesota satisfaction questionnaire. Minneapolis: University of Minnesota.

Wright, J. T. (1988), Conditions for effectiveness. In Fisher, J. L. \& Tack, M. W. (Eds.), Leaders on leadership: The college presidency, 87-91.

Wu, M. L. (2005), Human resource management: theory and practice, 4th ed., Taipei: Bestwise.

Wu, Y. J. (2017), Get started in the workplace relationship from the understanding of human nature, Career, 473, from the World Wide http://blog.career.com.tw/managing/communication_content.aspx?na_id=1084\&na_toolid=405. 